\title{
Historia del Clostridium botulinum
}

\author{
WALTER LEDERMANN D.*
}

\section{The History of Clostridium botulinum}

La historia de este bacilo se inicia oficialmente en 1820 , con las investigaciones realizadas por Justinus Kerner (1786-1862), en el reino de Würtenburg, sobre los envenenamientos producidos por salsas con carne, conocidos como botulismo (de botulus, salsa $)^{1}$. Suele afirmarse con ligereza que este investigador no era un científico, sino un poeta y místico, pero ya que no figura en las más rigurosas historias de la literatura ni en las mejores enciclopedias, debemos estimarlo como poeta "menor", a diferencia de su contemporáneo Theodor Kerner, gran vate militar, famoso por su Lira y espada ${ }^{2}$. El destino, burlón, conservó el nombre de nuestro poeta en la "enfermedad de Kerner", como se llamó al botulismo, y no ligado a poema alguno digno de recordarse.

En realidad Justinus era médico y alcanzó bastante fama en su profesión, en el curso de la cual tuvo, paradojalmente, una relación con la gran poesía cuando sólo era estudiante de medicina al cuidar al famoso escritor romántico Johann Christian Friedrich Hölderlin (1770-1843). Recordemos que Hölderlin, “a quien Apolo sonriera", luego de alcanzar la cúspide de su genio a la edad de 37 años, se hundió en una tranquila locura ${ }^{3}$, en la que permaneció 36 años en una torre de Tubinga ${ }^{4}$, al cuidado del ebanista Ernest Zimmer, escribiendo aún versos notables bajo el seudónimo de Scardanelli: según una teoría, no estaba loco y sólo "dejó de hablar al mundo porque no tenía ganas de hablar y no porque fuera incapaz de hacerlo"...j Ojalá muchos políticos siguieran su ejemplo ! En el hospital o clinicum de la Universidad de Tubinga, Suabia, había sólo 6 camas, de las cuales dos estaban dedicadas a pacientes psiquiátricos; en una de ellas era Holderlin atendido por el profesor Autenrieth, secundado por el alumno Justinus Kerner... ¿Cómo diablos, luego de conocer al divino Hölderlin en 1808, pudo el joven Justinus derivar hacia las salsas envenenadas en 1920? Como dijera el mismo Hölderlin:

\section{Diversas son las líneas de la vida} cual sendas y límites de montañas.

Tanto en Würtenburg como en el gran ducado de Baden eran frecuentes las intoxicaciones por el veneno de los embutidos o alantiasis, cuya alta mortalidad impactó a Kerner y también a Paulus, quien prosiguió las investigaciones en 1834. Entre 1793 y 1827 se registraron en Würtemberg 234 casos; y 400 hasta 1853 , con 150 fallecidos ${ }^{6}$. Müller publicó en 1869 y 1870 extensas monografías sobre el tema ${ }^{7,8}$, aprovechando el gusto de los alemanes por los em- butidos y las salsas de carne, que le suministraban abundante casuística.

A lo largo del siglo pasado el interés se fue centrando cada vez más en los embutidos, y hasta el mismo Virchow, que abominaba de las bacterias ${ }^{9}$, las buscó infructuosamente en estos alimentos. Van den Corput $^{6}$ postuló que el agente causal era un hongo, que denominó Sarcina botulina, el cual aparentemente sólo existió en su imaginación, pues nadie pudo cultivarlo. Bien pronto se observó que el veneno se encontraba en el centro de los embutidos, con mayor probabilidad cuanto más gruesos fueran éstos; que no se desarrollaba en presencia de oxígeno; que los embutidos no mostraban signos de putrefacción y que muchas veces eran frescos, recién preparados. Se pensó en ptomaínas, sustancias encontradas en cadáveres exhumados, así como en una serie de compuestos químicos, como ácidos prúsico, pícrico y grasos, o bases orgánicas volátiles. Hasta llegó a hablarse de un ácido botulínico... Sin embargo, el hecho más claro es que ninguna de estas sustancias podía reproducir en animales de laboratorio la característica parálisis del botulismo.

Entre 1895 y 1897, los microbiólogos belga Emile Pierre van Ermengem, de Ghent, y alemán Wilhelm Kempner, de Berlín, pondrían término a la incertidumbre, al demostrar que el botulismo era causado por la toxina de un bacilo anaerobio. Todo comenzó en diciembre de 1895, en la villa de Ellezelles, Hainault, Bélgica, donde concurrió una sociedad musical invitada para tocar una elegía funeraria. Después de la ceremonia fúnebre, la orquesta fue invitada a servirse una colación fría, donde el plato fuerte era un típico jamón salado. Este cerdo, narra el historiador William Bulloch ${ }^{10}$, había sido sacrificado cuatro meses antes, en agosto, "y en su estado fresco había sido parcialmente comido with impunity" El remanente quedó en salmuera hasta el día del mencionado funeral. Enfermaron 34 personas, incluyendo a todos los músicos, cuyos síntomas se presentaron entre las 24 y 36 horas siguientes a la ingestión e incluyeron estrabismo, diplopia, ptosis palpebral, afonía y disfagia. Tres intoxicados fallecieron, lo que arroja una letalidad cercana al diez por ciento. De los restos del jamón, así como del bazo de una de las víctimas aisló van Ermengem esporas de un bacilo anaerobio, que denominó Bacillus botulinus. Además, utilizando un filtrado del cultivo, libre de bacilos y de esporas, pudo reproducir en animales de laboratorio signos de parálisis, demostrando la existencia de una toxina.

Trabajando con la cepa del belga, Kempner logró 
producir en cabras una antitoxina neutralizante. A mayor abundamiento, la etiología del botulismo pudo ser rápidamente confirmada por Römer durante un pequeño brote en Hesse, en $1900^{11}$; y por Landmann y Gaffky $^{10}$, cuatro años después, al investigar en Darmstadt una epidemia provocada por la ingestión de porotitos en conserva. Este último brote fue muy significativo, pues era la primera vez que se involucraban alimentos vegetales en el botulismo.

Digamos, de paso, que también el primer brote documentado de botulismo en Chile, en la década de los setentas, fue provocado por porotitos en conserva, preparados para consumo interno por religiosas de una colectividad española. Las monjitas reían inocentemente porque veían doble, pero luego parálisis severas siguieron a la diplopia, y varias de las afectadas, de edad avanzada, fallecieron. Restos de los porotos fueron analizados, comprobándose la presencia de toxina bolutínica por el Instituto de Salud Pública, que recién había montado la técnica para su detección.

Sucesivos estudios a nivel mundial demostraron que el $C$. botulinum era capaz de producir 7 toxinas antigénicamente distintas, designadas con letras $\mathrm{A}$, B, C, D, E, F, G, en tanto que otras especies del mismo género, como $C$. barati y $C$. butyrum podían también producir intoxicaciones, al poseer toxinas similares a las $\mathrm{F}$ y E, respectivamente ${ }^{12}$. Todas estas toxinas actúan en la sinapsis periférica, en la placa motora, bloqueando la acetilcolina, con lo que generan parálisis muscular. La toxina A, la más frecuente y mejor estudiada, es termolábil, bastando calentar los alimentos a $80^{\circ} \mathrm{C}$ por un minuto para destruirla.

El interés por estudiar la toxina recrudeció a raíz de dos hechos: primero, la aparición de casos de botulismo en lactantes por la ingestión de miel, y segundo, su posible uso terapéutico.

En 1976 describió Picket ${ }^{13}$ los primeros casos de botulismo infantil, aunque Arnon, que ha estudiado el problema a fondo, piensa que en 1931 ya se habían presentado otros, no debidamente diagnosticados ${ }^{14}$. La hipótesis es que el bacilo esporula, las esporas son llevadas por el viento hasta los panales e infectan la miel. Engullida ésta, las esporas van al colon, germinan y liberan la toxina, que por vía hemática va a fijarse en las sinapsis. Experiencias en ratones demostraron que la microflora normal impide la colonización aunque la miel contenga hasta un millón de esporas, cifra que cae a diez si se trata de ratones criados cell-free ${ }^{15}$. Arnon logró reunir una casuística de 26 lactantes, menores de un año, que enfermaron entre los 14 y los 351 días de vida, porque sus torpes padres les dieron a comer miel conteniendo entre diez y cien esporas ${ }^{16}$. Considerando que la toxina botulínica es el veneno más potente conocido, con una dosis letal $50 \mathrm{de} 1 \mathrm{mg} / \mathrm{kg}$ peso corporal, los efectos fueron desastrosos. Algunos niños tuvieron muerte súbita ${ }^{17}$.

Más interesante y más productivo es el asunto del uso terapéutico. En 1885 ya Claude Bernard había dicho que "los venenos pueden emplearse tanto para destruir vidas como para el tratamiento de los enfermos"18; en 1968 los norteamericanos Allan Scott y Edward Schantz le tomaron la palabra e iniciaron los estudios de las bondades curativas de la toxina botulínica $^{19}$. La historia comenzó en 1943, durante la Segunda Guerra Mundial, cuando los servicios de inteligencia británicos informaron que los alemanes estaba estudiando bombardear toxinas sobre Gran Bretaña, usando como "vectores" las célebres bombas V-1. La Academia Nacional de Ciencias de EE.UU., a través de los profesores Fred y Baldwin y bajo los auspicios del ejército, montó un laboratorio en Camp Detrick (luego Fort Detrick) para investigar el problema de la guerra tóxica y proponer soluciones defensivas. Allí pudo Carl Lamanna obtener la toxina botulínica tipo A en su forma más pura y cristalina, con una fracción tóxica de 150.000 dalton, unida a otra fracción no-tóxica de 750.000 dalton que la protegía de la digestión enzimática en el intestino ${ }^{17}$. Los alemanes nunca llegaron a bombardear esporas o toxinas sobre Londres, pero los estudios de Fort Detrick no fueron inútiles y tuvieron una aplicación pacífica a partir de 1970, con un intento para controlar el estrabismo rebelde.

En 1972, Estados Unidos fue una de las naciones firmantes de la Convención de Armas Biológicas y Toxinas, que ponía término a la investigación en este campo, de modo que el presidente Nixon ordenó cerrar Fort Dixon para estos fines. Schantz se fue a la U. de Wisconsin y su investigación con la toxina botulínica se centró en su posible utilidad terapéutica y así pudo proporcionar a Scott la preparación que, con permiso de la FDA, éste inoculó a voluntarios humanos que sufrían de estrabismo, previo ensayos en monos rhesus ${ }^{20}$. Pronto las indicaciones se extendieron al blefarospasmo, ciertas formas de tortícolis y otros desórdenes musculares. En 1989 la FDA aprobó la toxina como orphan drug, siempre que proviniera del único lote certificado, uno de 200 mg fabricado en 1979 con la cepa Hall, capaz de generar diez millones de DL 50 para el ratón en 24 horas, en un medio muy simple. Las dosis terapéuticas se expresan en nanogramos, de los que 10 pueden curar una tortícolis ( si hay trastornos de la deglución, bajar la dosis) .

Gracias a la toxina botulínica, artistas que sufrían de distonías musculares han vuelto a tocar el piano y el violín, y de esta manera el Clostridium botulinum, que diezmara la banda musical de Ellezeles en 1895, ha podido casi un siglo después pagar su deuda con el arte.

No conozco ningún verso de Justinus Kerner que pudiera cerrar la historia de este bacilo, tan relacionada con la poesía y la locura, la música y la carne, la miel y la guerra, de modo que he de recurrir a su célebre paciente Hölderlin en la torre de Tubinga:

Su vida escoge el hombre, su objetivo, gana, libre de error, sabiduría, pensamientos y así contempla la verdad

y el más alto sentido

y las más singulares preguntas 
P.S. Was bleibet aber, siften es die Dichter ("Pero lo que permanece, lo fundan los poetas". Y esto último lo escribió, mis estimados científicos, cuando aún no estaba loco)

\section{Bibliografía}

1.- Schaffner W. Clostridium botulinum. En: Mandell, Douglas \& Bennett's Principles and Practice of Infectious Diseases. Mandell GL, Bennett JE and Dolin R, editors. 3rd. edit., Churchill Livingstone, NY 1990, pp: $1847-50$.

2.- De Riquer M, Valverde J M. El romanticismo alemán. En: Historia de la Literatura Universal, 7a. edic., Planeta S.A , Barcelona 1968; 3: 30-43.

3.- Peters Uwe Henrik. Hölderlin: el más famoso esquizofrénico alemán. El Mercurio 1997; 21 Diciembre: E $10-2$.

4.- Bruns F. Hölderlin, Johann Christian Friedrich. En: Collier's Encyclopedia. Crowell Collier and MacMillan Inc ,USA 1967; 12: 191-2.

5.- Hesse H. En el pabellón de Pressel. En : Libro de fábulas, Obras completas, Aguilar S.A. Ediciones, Madrid 1961; vol II: 1178-203.

6.- Eulenburg A. Botulismo. En : Diccionario Enciclopédico de Medicina y Cirugía prácticas, Agustín Jubera editor, Madrid 1886; t II: 113-9.

7.- Müller H. Botulus. Deuts Klin 1869; 22: 321-9.

8.- Müller H. Uber botulus. Deuts Klin 1870; 23: 27-36.

9.- Vaccarezza RF. Vida y obra de Robert Koch. En : Koch R. La etiología de la tuberculosis y otros trabajos. Editorial Universitaria, Buenos Aires 1965; p: 22.

10.- Bulloch W. History. En: Medical Research Council. A System of Bacteriology in Relation to Medicine, His
Majesty's Stationery Office, London 1929; vol III, chapter XI: 373-4.

11.- Römer P. C. botulinum in Hesse. Zblt Bakt 1900; I27: 857-67.

12.- Hatheway C L. Clostridium botulinum. En: Gorbach S L, Bartlett J G, Blacklow N R. Infectious Diseases. WB Saunders Co. Phi. 1992; 1583-7.

13.- Pickett J, Berg B, Chaplin E et al. Syndrom of botulism in infancy: clinical and electrophysiologic study. N Engl J Med 1976; 295: 770-2.

14.- Arnon S S, Werner S B, Faber H K et al. Infant botulism in 1931: discovered of a misclassified case. Am J Dis Child 1979; 133: 580-2.

15.- Arnon S S, Midura T F, Clay S A et al. Infant botulism : Epidemiological, clinical and laboratory aspects. JAMA 1977; 237: 1946-51.

16.- Arnon S S, Midura T F, Damus K et al. Honey and other environmental risk factors for infant botulism. J Pediatr 1979; 94: 331-5.

17.- Sonnabend O A R, Sonnabend W F F, Krech U et al. Continuous microbiological and pathological study of 70 sudden and unexpected infant deaths: Toxigenic intestinal Clostridium botulinum infection in 9 cases of sudden infant death syndrome. Lancet 1985; 1 : 237-40.

18.- Bernard C. An introduction to the study of experimental medicine, 1st edition, Mac Millan, N.York 1927.

19.- Schantz E J, Johnson E A. Botulinum toxin: the story of its development for the treatment of human disease. Persp Biol Med 1997; 40 (4): 317-27.

20.- Schantz E J, Johnson E A. Properties and use of botulinum toxin and other microbial neurotoxins in medicine. Microbiol Rev 1992; 56: 80-99. 